\title{
Venuti's Foreignization: Resistance Against The Arabic Culture
}

\author{
Fadil Elmenfi \\ Department of English , Faculty of Arts and Sciences \\ Omar Al-Mukhtar University \\ P.O Box 82, Derna City - Libya
}

Received: 25-10- 2013

Accepted: 24-12- 2013

Published: 10-01- 2014

doi:10.7575/aiac.ijclts.v.2n.1p.10

URL: http://dx.doi.org/10.7575/aiac.ijclts.v.2n.1p.10

\begin{abstract}
This paper gives a brief study on Domestication and Foreignization, and the disputes over these two basic translation strategies. Domestication designates the type of translation in which a transparent and fluent style is adopted to minimize the strangeness of the foreign text for the target language readers; while foreignization means a target text is deliberately produced to break target conventions by retaining something of the foreignness of the original.Most of Said's work have been translated into Arabic; some have been translated twice, and some three times. One of these translations forms the core of this paper, which attempts to discuss foreignization strategy. To accomplish this task, Edward Said's Orientalism (1978/2003) is chosen as the source text (ST), and the Arabic translation undertaken by Kamal Abu Deeb (1981/1995) is chosen as the target text (TT).
\end{abstract}

Keywords: Kamal Abu Deeb, Edward Said, Orientalsim, Domestication, Foreignization, Invisibility, Visibility, Translation Strategies.

\section{Introduction}

Translation is flourishing from day to day, as no day passes without a new book being translated from English into Arabic, and consequently new translation problems are raised. The fact is that with every new text in Modern Standard Arabic (MSA), the language almost invariably used in translation, new modes of thought and styles are presented, which may challenge the idiomatic modes with which the Arabic reader is familiar.

Translation theories could be said to have developed in the second half of the twentieth century. In addition, translation theory provides a framework of principles, rules, and disciplines for rendering and analysing texts. Newmark (1988: 37) says "translation theory attempts to give some insights into the relation between thought, meaning, and language". The variety of translation models is a reflection of the development in modern linguistics. In this context, Gentzler (2001: 43) sees that with the application of general linguistic theory, the theory of translation has been developed. Modern linguistics attempts to provide theoretical clarifications of the nature of both language and the translation process.

Most translators with no doubt wish to see their role in such a positive way: 'opening a window' for TT readers, in order to illuminate an unfamiliar culture for them. However, translation theorists have often seen their work in terms of much more negative, even violent images. As early as the 5th century, St Jerome used a military image to convey his strategy of translating sense-for-sense (as opposed to the common Roman practice of word-for-word translation): the translator "[carries] meaning over into his own language, just like prisoners, by right of conquest" (quoted in Steiner (1975:267), Steiner's translation). Throughout the centuries, translation theorists have wrestled with the question of the translator's attitude towards the foreign culture represented by the ST: is the translator opening a window onto that culture, or colonizing it by force?

In today's translation circles, the translations accepted by mainstream translation norms more often than not share such features as fluency, smoothness and transparency. The target text is free of the slightest trace of translation and reads as if it had been written by the original author in the target language. The differences, including the foreignness, strangeness, and otherness, are replaced by something familiar to the target reader. While such replacement makes it easier for the target reader to understand translation, it minimizes the foreignness of the target text. The abovementioned translating strategy is actually what the American translation theorist Lawrence Venuti (1995) termed in his book 'The translator's invisibility': A history of translation, the domesticating method, as opposed to another strategy, the foreignizing method.

\section{Domestication and Foreignization in Translation}

Venuti was the first to draw the critical distinction between domestication and foreignization in such a stark way in 1995. These terms can be traced back to the essay, On the Different Methods of Translation (1813), written by Schleiermacher. He mentioned that there are only two ways of translation: either the translator puts the author aside as far as possible, and moves the reader towards him; or he does the same to the reader, and moves the author towards him (Venuti, 1995, p. 42). He opined that the first one meant taking the reader over to the foreign culture and make him or her feel the linguistic differences, while the second meant the opposite, which is forming the text in a way to be familiar 
to the readers, in other words, bringing the foreign culture closer to the reader in the target culture. Venuti (1995, 20), in his book, the Translator's Invisibility, named the first method the foreignizing method, and the second the domesticating method. In that book, Venuti discussed the two methods in the context of society, politics, ideology and history, criticizing translation activities of the previous ages and informing us that fluent translation has always been in a commanding position in the history of translation of the western world. He added that the domesticating method dominates Anglo-American culture which requires fluent translating. Under the norms of fluency, the target text includes no traces of translation that can be seen, and is read as if it had been written by the original author in the target language. The differences existing between the two languages are replaced by something familiar to the target language readers. Such replacement makes it easier for the target language readers to understand and to follow the translated texts, and it minimizes the foreignness of the target text. Foreignizing method, however, seeks to restrain the ethnocentric violence of translation, and it is a strategic cultural intervention in the current state of world affairs. Venuti as a matter of fact, advocates foreignizing method which is called resistance with the hope to revolt the suzerain culture in ex-colonized countries and regards it as a form of resistance against ethnocentrism and racism, culture narcissism and imperialism.

Munday (2001:146-147) elaborates that Venuti (1995:21) sees domestication as controlling Anglo-American translation culture. In the same way as the postcolonialists are capable of understanding the cultural influences of the differential in power relations between colony and ex-colony, so Venuti (1995:20) complains about the problem of domestication as it involves an ethnocentric reduction of the foreign text to Anglo-American target language cultural values. This necessarily needs rendering in a transparent and invisible style so as to reduce the foreignness of the TT as much as possible. On the other hand, foreignization, which Venuti sometimes refers to as resistance (1995:305-6), is a nonstandard style of translation designed to make the translator's presence visible by emphasizing the foreign identity of the ST.

Venuti as well, argues that "domestication" further covers adherence to domestic literary canons by carefully selecting the texts that are likely to lend themselves to such a translation strategy (see Venuti 1997:241), whereas foreigniztion necessitates opting for a foreign text as well as developing a method of translation that would not include dominant cultural language (see Venuti 1997:242). Domestication therefore, can be regarded as the attempt to take all the essential measures and modifications of the ST to achieve a connection in effect, while foreignization is the attempt determined by the translator to keep the flavour and the touch of the original text, as can be seen by the use of special vocabulary or sticking to the original syntax.

\subsection{Visibility and Invisibility}

Invisibility is a concept used by Lawrence Venuti "to describe the translator's situation and activity in contemporary Anglo-American culture" (see Venuti 1995:1). He (ibid :1) argues that "invisibility refers to two mutually determining phenomena: one is an illusionistic effect of discourse, of the translator's own manipulation of English; the other is the practice of reading and evaluating translations that has long prevailed in the United Kingdom and the United States, among other cultures, both English and foreign-language."

Lawrence Venuti (ibid :1) sees this invisibility as typically being produced by the way translators themselves tend to translate "fluently" into English, to produce an idiomatic and readable TT, thus creating an "illusion of transparency", and by the way the translated texts are typically read in the target culture: "A translated text, whether prose or poetry, fiction, or non-fiction, is judged acceptable by most publishers, reviewers, and readers when it reads fluently, when the absence of any linguistic or stylistic peculiarities makes it seem transparent, giving the appearance that it reflects the foreign writer's personality or intention or the essential meaning of the foreign text - the appearance, in other words, that the translation is not in fact a translation, but the "original" (see Venuti $1995: 1$ ).

As previously indicated, Venuti discusses invisibility abreast with two methods of translating, namely domestication and foreignization. These are related to both the choice of text to translate and the translation method. Venuti traces these concepts back to Friedrich Schleiermacher and his 1813 essay "On the Different Methods of Translating." For Venuti (1995:21) "the Anglo-American culture . . . has long been dominated by domesticating theories that recommend fluent translating. By producing the illusion of transparency, a fluent translation masquerades as true semantic equivalence when it in fact inscribes the foreign text with a partial interpretation, partial to English-language values, reducing if not simply excluding the very difference that translation is called on to convey".

By the "illusion of transparency" Venuti (1995:1) refers to the "effect of fluent discourse, of the translator's effort to insure easy readability by adhering to current usage, maintaining continuous syntax, fixing a precise meaning". Venuti uses the expression "ethnocentric violence" to refer to the process of inscribing "the foreign text with a partial interpretation" and "reducing" or even "excluding the very difference that translation is called on to convey". This type of violence, for Venuti, takes place at many levels; he (1996:196) writes "The violence of translation resides in its very purpose and activity: the reconstitution of the foreign text in accordance with values, beliefs, and representations that pre-exist it in the target language, always configured in hierarchies of dominance and marginality, always determining the production, circulation, and reception of texts."

In contrast, foreignizing translation according to Venuti (1995:20) "seeks to restrain the ethnocentric violence of translation, it is highly desirable today, a strategic cultural intervention in the current state of world affairs, pitched against the hegemonic English-language nations and the unequal cultural exchanges in which they engage their global 
others. Foreignizing translation in English can be a form of resistance against ethnocentrism and racism, cultural narcissism and imperialism, in the interests of democratic geopolitical relations."

For Venuti (1996:198) "Foreignizing translation signifies the difference of the foreign text by disrupting the cultural codes in the target language" and "seeks to restrain the ethnocentric violence of translation".

Antoine Berman's work seems to have influenced Venuti regarding the issues of foreignization and domestication. In his very interesting essay "Translation and the trials of the foreign," Antoine Berman (2000: 284) writes "Translation is the trial of the foreign. But in a double sense. In the first place, it establishes a relationship between the Self-Same (Propre) and the Foreign by aiming to open up the foreign work to us in its utter foreignness.... In the second place, translation is a trial for the Foreign as well, since the foreign work is uprooted from its own language-ground. And this trial, often an exile, can also exhibit the most singular power of the translating act: to reveal the foreign work's most original kernel, its most deeply buried, most self-same, but equally the most 'distant' from itself."

This means that Berman is calling for showing the strangeness of the foreign work. He (2000: 285) wants "the language of the original shakes with all its liberated might the translating language". More importantly, Berman examines the tendency of neglecting and negating "the Foreign" in translation through naturalization." Antoine Berman (ibid: 286) argues that there is generally a "deforming system" (or "deforming forces")" in TTs that prevents the foreign from showing up in translation. He (ibid: 286) calls these systems or forces "the negative analytic"; he states "The negative analytic is primarily concerned with ethnocentric, annexationist translations and hypertextual translations (pastiche, imitation, adaptation, free writing), where the play of deforming forces is freely exercised. Every translator is inescapably exposed to this play of forces, even if he (or she) is animated by another aim."

The above quote leads to the issue of ideological (ethnocentric) tendencies that determine translation strategies and, hence, the way translations should be done and, above all, decide and frame the task of the translator. Moreover, it also implicitly entails the existence of hidden ideological agendas that play behind the scenes to control and dominate the process of translating: "Every translator is inescapably exposed to this play of forces, even if he/she is animated by another aim." Such forces are so powerful that they are inescapable. In this context, then, it is worth mentioning that Antoine Berman (2000:288) believes that "these forces, inherent in translating, are universals, rejecting, at the same time, that they are historical." He (ibid: 288) argues that "they are rather historical in an original sense. They refer back to the figure of translation based on Greek thought in the West or more precisely, Platonism." The 'figure of translation' is understood here as the form in which translation is deployed and appears to itself, before any explicit theory. From its very beginnings, western translation has been an embellishing restitution of meaning, based on the typically Platonic separation between spirit and letter, sense and word, content and form, the sensible and the non-sensible. When it is affirmed today that translation (including non-literary translation) must produce a "clear" and "elegant" text (even if the original does not possess these qualities), the affirmation assumes the Platonic figure of translating, even if unconsciously. All the tendencies noted in the analytic [listed below] lead to the same result: the production of a text that is more "clear," more "elegant," more "fluent," more "pure" than the original. They are the destruction of the letter in favour of meaning." So, obviously, these forces play on a larger scale than that of the translator's independent, free and personal choices, preferences, and/or decisions.

\subsection{Foreignization in Relation to Rhetorical Translation}

Rhetoric is the art of speaking and writing effectively. It helps in examining and discovering who we are and in explaining that identity to others. Aristotle (1984: 24) defined rhetoric as "the faculty of observing in any given case the available means of persuasion". While classical rhetoric was concerned primarily with persuasion, modern rhetoric has broadened its scope. Today, a rhetorical argument is used in a broader meaning of proof of a writer's position, development of his thoughts, or support for his perspectives. Winifred Horner (1973: 18) writes "all rhetoric, ancient and modern, is potentially empowering, giving power to find a voice, power to put ideas into words for an audience, power to gain willing belief and acceptance, and, therefore, power to affect, and perhaps even change the world".

Rhetoric can empower the postcolonial writer's voice through faithful and effective translation. Writers write to make their voices heard, to make their ideas come alive, and to appeal to an audience, and perhaps even change the world. Postcolonial writers' words are particularly empowered through rhetoric and rhetorical devices. At the same time, rhetoric can assist in the study of postcolonial translation in a substantial manner, offering writers, translators, and readers a broader view of the linguistic, cultural, and historical layers embedded in any act of reading, writing, and translation. Such a rhetoric becomes more important in the context of translating postcolonial writing because the target-source power relationship may lead to domestication and loss of the source culture. The power play, however, continues in the relationship through postcolonial texts that resist domestication of the source culture. The postcolonial translator's rhetorical task lies in capturing the writer's culture without domesticating it. Its translation should avoid domestication of the source culture in the target language, thereby allowing the target language and culture to be affected by the source language and culture.

The rhetoric and the ethics of translation involve faithful interpretation of the representation of the writer's culture, as well as faithful transplantation of the linguistic aspects of the original text as they, too, carry cultural traces. The translator's rhetorical and ethical task is to capture the source language sensibilities that are ever present in the target text. The translator's ethics lie not only in resisting any domestication of the writer's culture, but also in recapturing and recreating a different world-view that risks getting lost in translation. Inasmuch as translation aims to establish communication among different cultures, it must cultivate rhetorical and ethical means for doing so. Thus, an effective 
rhetoric of translation is necessary to preserve and represent a writer's cultural experiences as expressed in the original text. Rhetoric of translation also involves retaining foreign words and expressions, showing greater respect toward foreign cultures.

\title{
3. The Translation of Orientalism
}

In 1981, the first translation of Orientalism appeared, undertaken by Kamal Abu Deeb; it was very difficult and complex. In this respect, Sabry Hafez (2004:82) states that "Aside from obfuscating his brilliant argument, the translation had an enormous negative impact on his legacy and the perception or misperception of his work among Arab intellectuals. Its thick verbosity, pretentious terminology, and confused vocabulary associated him with the type of sterile and problematic language that was the hallmark of the coterie of Adonis, a clique that clung to Said for some time and complicated the way he was perceived in Arab intellectual circles for years". He goes on to say that "though the message of Said's Orientalism was distorted in Arab intellectual circles and indeed among the wider public through the traditionalists' widely disseminated misrepresentation of his main thesis as a kind of identity politics, the book did spark wide debate on the issues it addressed". By the same token, Edward Said himself, in the last chapter of Orientalism which he added to the 1995 edition and which was published after the Arabic translation of Abu Deeb appeared, described Abu Deeb's translation as having differences and made many comments on it.

Abu Deeb made a great effort to almost completely avoid using western expressions which already exist in Arabic. According to Edward Said:

\begin{abstract}
"I regret to say that the Arabic reception of Orientalism, despite Kamal Abu Deeb's remarkable translation, still managed to ignore that aspect of my book which diminished the nationalist fervour that some inferred from my critique of Orientalism, which I associated with those driven to domination and control, also to be found in imperialism. The main achievement of Abu Deeb's painstaking translation was an almost total avoidance of Arabized Western expressions; technical words like discourse, simulacrum, paradigm, or code were rendered from within the classical rhetoric of the Arab tradition. His idea was to place my work inside one fully formed tradition, as if it were addressing another from the perspective of cultural adequacy and equality." (Said
\end{abstract} 1978/2003:339)

Kamal Abu Deeb decided to restrict himself voluntarily to what he called representation of the translated text, which means representing the entire structure of the text, not an idea only. He started by alluding to the difficulty of Edward Said's book in both reading and translating. The sources of difficulty in the translation of Orientalism are not a single dimension, but multiple. The difficulty lies in Orientalism as much as in the development of the Arabic language. Edward Said is able to deal with language in all dimensions. In respect of such a thought, one's response is not determined in the context of easy and difficult, but in a different context and at a different level: the level of ability to use the most difficult level in analysis, the most ambiguous concepts in the discussion of what seems ordinary (see Abu Deeb 1981/1995:9).

In the coming discussion we will see how Abu Deeb's translation followed a new method of translation as a pretext to enrich Arabic literature and culture, and we will also see how the status of Said in the Arab world and the wide circulation of Orientalism may have motivated one of the major translators in the Arab world to undertake retranslating the same text after a quarter of a century.

\subsection{Foreignizing Concepts}

If the Arabic reader decides to read the translated copy of Orientalism by Kamal Abu Deeb, he/she will encounter problems with the lexical vocabulary, and the complex linguistic forms. In this respect, Sabry Hafez in his article "Edward Said's Intellectual Legacy in the Arab World", which was published in the Journal of Palestine Studies (2004: 81-82) notes that the translated version of Orientalism is complex, ambiguous and has a number of problems. He basically thinks that the critical issue is the transformation of a lucid and interesting book into a confusing text with incomprehensible terminology. Despite Said's brilliant discussion, the translation has a completely negative effect on his legacy and the intellectual's understanding or misunderstanding of his work. The heavy verbosity, and the created terminology, associates him with a problematic language.

By the same token, Abu Deeb's complexity formed by the totally novel terminology that he devised, do not contribute to making the text more clear and comprehensible; on the contrary, they seem to create complexity, as well as making the reader's task much more difficult and, as has already been mentioned above, although the new vocabulary is in his mother tongue, it is hard to interpret without great effort. The following examples clarify this point.

\begin{tabular}{|c|c|c|}
\hline 1 & Euphemism & اللبقة الاستبالية \\
\hline 2 & Satellite Relationship & التكوكبية (علاقة) \\
\hline 3 & Grid & مشبك \\
\hline 4 & Dynamics & فو اعل الحيوية \\
\hline 5 & Passion & شبوب عاطفي \\
\hline
\end{tabular}




$\begin{array}{ccc}6 & \text { Demystification } & \text { تقوط السرية } \\ 7 & \text { Mediation } & \end{array}$

Despite the fact that Abu Deeb's book includes footnotes in which he provides explanations of the coined terms, these explanations do not help the reader with the process of interpreting the meanings of the above terms, such as:

"الاستبدالية اللبقة (Euphemism) : تجنب تسمية شيء باسمه المباشر لعوامل أخلاقية أو نفسية. الغائط، مثلاً، لفظة استبدالية لبقة."

"التكوكبية (علاقة) (Satellite Relationship): علاقة التبعية، كما يدور قمر صناعي حول الأرض مثلا." (1980:24) Abu Deeb)

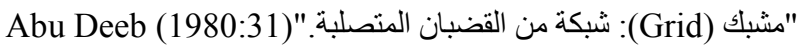

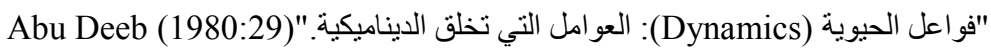

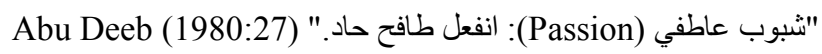

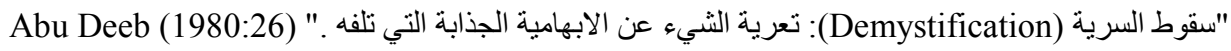
"توسط (Mediation): بالمعنى البنيوي التوسط بين طرفي ثنائية ضدية لتخفيف التضاد بينهما."(1980:25) Abu Deeb)

Even if the reader, in a particular case, is able to understand the given explanation of a certain term, he would wonder why the translator is using that particular novel term instead of another term that is already well-known in the Arabic language. This is a clue of how complex Abu Deeb's style is. From the above discussion we can say that the ambiguity of Abu Deeb's translation directly affected understanding the style of the book to a great extent, and this created an unpleasant impact on the reader.

\subsection{Foreignizing Western Terms and The Stylistics Effects}

Terms and expressions of some western concepts such as: imperialism, positivism, utopianism, historicism, Darwinism, Spenglerism, paradigm and Baconian, are rendered by Abu Deeb into new and unfamiliar Arabic equivalent terms. To clarify this point further, consider these examples:

\section{Example (1):}

“Orientalism has been subjected to imperialism, positivism, utopianism, historicism, Darwinism, racism, Freudianism, Marxism, Spenglersim. But Orientalism, like many of the natural and social sciences, has had 'paradigms' of research, its own learned societies, its own Establishment" (Said, 1978/2003:43)

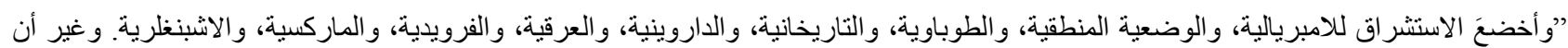

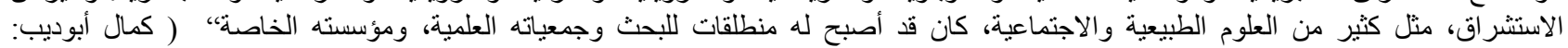

(74 - 1995/1981

\section{Example (2):}

"Two great themes dominate his remarks here and in what will follow: knowledge and power, the Baconian themes." (Said 1978/2003:32)

"بطغى على ملاحظات بلفور، هنا وفيما سيتلو، موضو عان عظيمان: المعرفة والقوة، الموضو عان البيكونيان"، ( كمال أبوديب: 1995/1981 - 64)

\section{Example (3):}

"Cromer's descriptions are of course based partly on direct observation, yet here and there he refers to orthodox orientalist authorities (in particular Ernest Renan and Constantin de Volney)" (Said 1978/2003:39)

"ويقوم وصف كرومر، طبعاً على الملاحظة المباشرة جزئياً، غير أنه من حين لآخر يشير إلى أعمال مستشرقين ثقات سُنيين (أرثوذكسيين) (وبشكل خاص

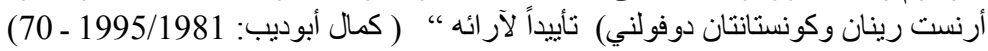

In the above examples, Said uses terms to express western concepts such as: positivism, utopianism, historicism, and orthodox. The Arab reader (other than highly educated people and experts) is unfamiliar with these concepts and their labels. Abu Deeb translates them as: الوضعية المنطقية، والطوباوية، والتاريخانية، وسنبينين which are completely different from the ordinary terms used by ordinary educated Arab people: الفلسفة الو اقعية ـ طو باوية ـ النزعة التاريخية ـ التعصبية.

Comparing the translations of the terms listed above with those of Abu Deeb, one can easily notice the difference in meanings, as Abu Deeb's renditions are new and different. For instance, he rendered the Christian religious term 'orthodox orientalist authorities' أرثوذكسيين مسنشرقين ثقات سنيين). In this case, the western Christian word 'Orthodoxy' is translated as السُنّية 'which refers not only to the restricted meaning of the Islamic Sunni sect but also to the general attitude of conservatism too. Another example is the rendition of "paradigms" by the translator as منطلقات للبحث . None of the Arabic dictionaries furnish the Arabic meaning given by Abu Deeb, as it is shown in the words listed in the index of terms that Abu Deeb added at the beginning of his book Orientalism. This shows that the translator has understood the following western terms both contextually and pragmatically: positivism, utopianism, historicism, orthodox and paradigm and consequently rendered them pragmatically rather than semantically. The Arabic rendition الوضعية المنطقية however, might not be easily understood by the normal Arab addressee, and the word "paradigms" is not easily understood by the normal Western reader. But, in my opinion, these terms will remain easy to understand by the Western reader rather than the Arab reader, for no reason, but because these terms are originated in the West.

As seen above, matching word with word, structure with structure and sentence with sentence is Abu Deeb's approach to translation. He is able to deal with the original text without explaining or simplifying it. According to Abu Deeb 
(1981/1995:12) this needs courage, innovation and adventure to deal with the language as a continuous process of creating idioms and coining new terms and not to regard the language as a sacred issue. In my humble opinion, Abu Deeb should deal with texts in a more flexible and simple way, rather than creating complex text that contain novel vocabulary which would cause much confusion to the TT readers. Coining new terms and the process of their entry to societies will demand effort and time to be adapted as part of one's own language.

Many Arab writers and intellectuals, such as Asa'ad Abukhalil and Muhammad al- Ahamari criticized Abu Deeb's attempt to "implode" the language for the sake of enhancing its ability to accommodate various developments.

Al-Herthani (2009:146) declares that Abu Deeb's intention was to empower the Arabic language and to make it capable of standing on an equal footing with other world languages. In some respects the changes he makes are reminiscent of the foreignizing strategy of Venuti, which are adopted in the context of "a theory and practice of translation that resists dominant target-language cultural values" (see Venuti 1995: 23). In order to disrupt the dominant language, Venuti espouses this method i.e. disrupting English, and stresses that it is "specific to certain European countries", and that it is used to challenge "ethnocentrism and racism, cultural narcissism and imperialism" (see Venuti 1995: 20).

Abu Deeb's method was not a success because it minimized the importance of Arabic; the Arabic language became unable to be understood by its speakers according to Mona Ibrahim (2004:1032). Immersed in his conceptual narrative of language and translation she noted that Abu Deeb failed to consider the modern Arab audience's needs and power relations that characterise the world today. Mona Ibrahim (ibid: 1032) states that his claim of invisibility is false given the [obvious] signs of his dominating presence. The failure to consider the power relations that characterise the modern world is the major failing of this translation which leads to the assimilation of the Anglo-American mechanisms of cultural hegemony over the third world countries, and that Abu Deeb's translation is hardly resistant at all, if not submissive altogether.

\section{Conclusion}

The aim of this paper was to identify the concepts of domestication and foreignization in relation to other interrelated aspects which made us see that if the ST is totally domesticated, it becomes totally removed from its time and place, and TT readers lose the opportunity of experiencing the cultural capital of a different civilization. On the other hand, if it is totally foreignized, it will be difficult to read; in Bassnett and Lefevere's words (1998:11), such translations become "so low on the entertainment factor that they appeal only to those who read for professional reasons". Furthermore, TT readers cannot identify with the people speaking in the text because they are culturally too remote from them.

Abu Deeb (1981/1995:09) states that he would be simplifying the matter if he described Said's book as being difficult, for both reading and translating. He also regards Said's style as being very sophisticated, to the extent that he is able to deal with the English language at all levels. However, as we have seen in previous analyses attempted in the present article, Abu Deeb's translation method can be said to be less effective, as he supports mechanical transference of structure, in addition to the obscurity and ambiguity as seen in the examples supplied in the present paper.

This analysis has suggested that Abu Deeb's method was foreignization, because he calls for a mechanical transference of structure, thus rendering the TT not just "foreign" but obscure and ambiguous as seen in the examples analysed in the present article. To sum up, Abu Deeb employs this technique to enrich Arabic literature and culture and he experiments with the Arabic language when he renders Said's texts, as a part of the his project. However, his translations of Orientalism proved controversial in the Arab World.

The translation of Orientalism by Abu Deeb was certainly constructed in a way that would influence the reception of the book and its author in the Arab world for a considerable number of years. Abu Deeb's translation choices labeled Said's writing as inaccessible and complex and demanding an outstanding level of intelligence from the reader.

\section{References}

Al-Herthani, M. (2009) Edward Said in Arabic: Narrativity and Paratextual Framing. Unpublished PhD thesis. University of Manchester.

Aristotle (1984) The Complete Works of Aristotle. Rhetoric and Poetics, the revised Oxford Translation, vol. 2. Jonathan Barnes, ed. Princeton/Bollingen Series LXXI.2, Princeton University Press.

Berman, A. (2000) "Translation and the Trials of the Foreign", The Translation Studies Reader. Ed. Lawrence Venuti. New York and London: Routledge, p 276-289.

Gentzler, E. (2001) Contemporary Translation Theories, Clevedon: Multilingual Matters.

Hafez, S. (2004) "Edward Said's Intellectual Legacy in the Arab World", Journal of Palestine Studies, 33 (3), p76-9081-82.

Horner, W. (1973) Rhetoric in the Classical Tradition, New York: St. Martin's Press.

Ibrahim, Mona (2004) إدوارد سعيد: الخفي شديد الظهور: قراءة ما بعد كولنيالية لترجمة كمال أبوديب [Edward Said: The Most Apparent Hidden: A Postcolonial Reading of Abu Deeb's Translation of Said's Orientalism] Conference Proceedings, Cairo: Supreme Council of Culture: p 1019-1035.

Munday, J. (2001) Introducing Translation Studies: Theories and Applications, London: Routledge.

Newmark, P. (1988) A Textbook of Translation, New York: Prentice Hall. 
Said, E. (2003) Orientalism, London: Penguin.

Said, E. (2006) Orientalism, trans. Muhammad Enani, Cairo: al-Ru’ya for Publishing and Distribution.

Said, E. (1981) Orientalism, trans. Kamal Abu Deeb, Beirut: Institute for Arab Research.

Susan, B. and Lefevere A. (1998) Translation, History and Culture. London and New York: Pinter.

Venuti, L. (1995) The Translator's Invisibility: a History of Translation, London and New York: Routledge.

(1997) "Translation as a Social Practice: Or, The Violence of Translation", In M.G. Rose (ed.) Translation

Horizons Beyond the Boundaries of Translation Spectrum [Translation Perspectives IX), Binghamton: State U of New York at Binghamton, p 195-213. 